\title{
Proposal for Rejection of Agrobacterium tumefaciens and Revised Descriptions for the Genus Agrobacterium and for Agrobacterium radiobacter and Agrobacterium rhizogenes
}

\author{
HIROYUKI SAWADA, ${ }^{1}$ HIROYUKI IEKI, ${ }^{1}$ HIROSHI OYAIZU, ${ }^{2 *}$ \\ AND SATOSHI MATSUMOTO ${ }^{2}$ \\ Akitsu Branch, Fruit Tree Research Station, Akitsu, Hiroshima $729-24,{ }^{1}$ and Faculty of Agriculture, \\ The University of Tokyo, Bunkyo-ku, Tokyo 113, Japan
}

\begin{abstract}
The 16S rRNA sequences of seven representative Agrobacterium strains, eight representative Rhizobium strains, and the type strains of Azorhizobium caulinodans and Bradyrhizobium japonicum were determined. These strains included the type strains of Agrobacterium tumefaciens, Agrobacterium rhizogenes, Agrobacterium radiobacter, Agrobacterium vitis, Agrobacterium rubi, Rhizobium fredii, Rhizobium galegae, Rhizobium huakuii, Rhizobium leguminosarum, Rhizobium loti, Rhizobium meliloti, and Rhizobium tropici. A phylogenetic analysis showed that the 15 strains of Agrobacterium and Rhizobium species formed a compact phylogenetic cluster clearly separated from the other members of the alpha subclass of the Proteobacteria. However, Agrobacterium species and Rhizobium species are phylogenetically entwined with one another, and the two genera cannot be separated. In the Agrobacterium species, the strains of biovar 1, biovar 2, Agrobacterium rubi, and Agrobacterium vitis were clearly separated. The two biovars exhibited homogeneity in their phenotypic, chemotaxonomic, and phylogenetic characteristics, and two species should be established for the two biovars. We considered the nomenclature of the two biovars, and revised descriptions of Agrobacterium radiobacter (for the biovar 1 strains) and Agrobacterium rhizogenes (for the biovar 2 strains) are proposed. The name Agrobacterium tumefaciens is rejected because the type strain of this species was assigned to Agrobacterium radiobacter, and consequently the description of the genus Agrobacterium is revised.
\end{abstract}

The genus Agrobacterium was established by Conn (4) in 1942. This genus has been a member of the family Rhizobiaceae since it was first established. The members of the family Rhizobiaceae have a unique ability to induce cortical hypertrophies on plants (26). The genera Rhizobium and Bradyrhizobium are well-known nitrogen-fixing noduleforming bacteria associated with legumes. The members of genus Phyllobacterium induce the formation of nodules on the leaves of certain plant species.

All of the members of the genus Agrobacterium except Agrobacterium radiobacter induce cortical hypertrophy of the upper parts of roots (Agrobacterium tumefaciens and Agrobacterium rubi) or abnormal root growth (Agrobacterium rhizogenes) on many kinds of plants. Many non-tumorforming strains closely related to the tumor formers which have been found in soil or in the rhizospheres of plants $(3,4)$ and in clinical specimens (13) have been identified as Agrobacterium radiobacter strains $(4,26)$. Later, molecular biological studies have revealed that the tumor- or hairy-rootforming ability is due to the presence of large indigenous plasmids $(22,23,30,33,46,49,52)$, and the inclusion of the organisms that do not form tumors in the genus Agrobacterium has been confirmed. Also, recent rRNA-DNA homology studies $(9,19)$ have revealed the close relationship between the non-tumor-forming strains and the tumor formers.

The separation of the genus Agrobacterium from allied genera and also the separation of species in the genus Agrobacterium are based strictly on phytopathogenic characteristics (26). Most of the genes associated with tumor and hairy root formation are located on Ti or Ri plasmids $(22,23$, $30,33,46,49,50,52$ ), and therefore the present system used

\footnotetext{
* Corresponding author.
}

for differentiation of species in the genus Agrobacterium is not based on chromosomal DNA. However, the taxonomy of bacteria should be grounded upon chromosomal DNA. In addition to pathogenicity studies, a lot of conventional characterization studies $(17,18,21,39,40)$, a chemotaxonomic study (42), DNA-DNA (15) and DNA-rRNA homology $(9,19)$ studies, and numerical studies $(14,25,50)$ have been performed with members of the genus Agrobacterium. As a consequence of such a large number of comparative studies, three biovars and one peculiar member (Agrobacterium rubi $[16,44])$ have been recognized. The biovars now referred to as biovars 1 through 3 should be assigned to three species $(17,18)$. Very recently, Agrobacterium vitis was established for the biovar 3 strains (35). However, separation of the biovar 1 and 2 strains is still based on the phytopathogenicity of the organisms, and biovars 1 and 2 do not have taxonomic status.

In this study we sequenced the whole 16S rRNA gene for seven selected Agrobacterium strains, including members of three biovars of the genus Agrobacterium, Agrobacterium rubi, and unclassified strains, and for eight representative strains of the genus Rhizobium. We propose the following revised taxonomy: Agrobacterium radiobacter should replace Agrobacterium biovar 1, and Agrobacterium rhizogenes should replace Agrobacterium biovar 2. As a result of the revised description of Agrobacterium radiobacter (this taxon includes the type strain of Agrobacterium tumefaciens), the name Agrobacterium tumefaciens should be rejected. The description of the genus Agrobacterium is revised; the type species is Agrobacterium radiobacter.

\section{MATERIALS AND METHODS}

Bacterial strains. The 16S rRNA sequences were determined for biovar 1 strain NCPPB 2437 (National Collection 
of Plant Pathogenic Bacteria, Harpenden, Hertfordshire, United Kingdom) (the type strain of Agrobacterium tumefaciens) (= ATCC 23308), biovar 2 strain IFO 13257 (Institute for Fermentation, Osaka, Japan) (the type strain of Agrobacterium rhizogenes) (= ATCC $11325=$ NCPPB 2991), biovar 3 strain NCPPB 3554 (the type strain of Agrobacterium vitis), strain IFO 13261 (the type strain of Agrobacterium rubi) (= ATCC $13335=$ NCPPB 1854), strain NCPPB 1650, strain K-Ag-3 isolated from tumor produced on Actinidia chinensis in Hiroshima Prefecture, Japan, and strain Ch-Ag-4 isolated from Prunus species in Okayama Prefecture, Japan. Strains NCPPB 1650, K-Ag-3, and Ch$\mathrm{Ag}-4$ belonged to peculiar groups of the genus Agrobacterium on the basis of their phenotypic characteristics $(25,39)$. Detailed isolation procedures have been described previously $(39,40)$. The $16 \mathrm{~S}$ rRNA sequences were also analyzed for Rhizobium fredii ATCC $35423^{\mathrm{T}}$ (T = type strain), Rhizobium galegae ATCC $43677^{\mathrm{T}}$, Rhizobium huakuii IFO $15243^{\mathrm{T}}$, Rhizobium leguminosarum IAM $12609^{\mathrm{T}}$ (Institute of Applied Microbiology, The University of Tokyo, Tokyo, Japan), Rhizobium loti ATCC $33669^{\mathrm{T}}$, Rhizobium meliloti IAM $12611^{\mathrm{T}}$, Rhizobium tropici IFO $15247^{\mathrm{T}}$, Bradyrhizobium japonicum IAM $12608^{\mathrm{T}}$, Azorhizobium caulinodans ORS $571^{\mathrm{f}}$ (Collection de l' Institut Français de Recherche Scientifique pour le Développement en Coopération [ORSTOM], Dakar, Senegal), and Rhizobium species strain OK55 isolated from a nodule of Sesbania aculeata in Okinawa Prefecture, Japan.

Sequencing of $16 \mathrm{~S}$ rRNA. For sequencing, the bacteria were cultured in arabinose liquid medium (31) for $24 \mathrm{~h}$ at $28^{\circ} \mathrm{C}$. The sequences of the $16 \mathrm{~S}$ rRNAs were determined mostly by the polymerase chain reaction (37), using the following method. Total DNA from ca. $50 \mathrm{mg}$ (wet weight) of cells was extracted and purified by repeated phenol treatment followed by RNase treatment. The 16S rRNA coding region of the DNA was amplified from the total DNA by using two primers that attached to positions 10 to $25\left(5^{\prime}\right.$. AGTTTGATCCTGGCTC-OH-3') and 1541 to 1525 (5'AAGGAGGTGATCCAGCC-OH-3') (Escherichia coli numbering system) and Taq DNA polymerase (Cetus, Inc.). The amplified DNA was purified by the glass bead method, using an Easytrap kit (Takara Shuzo, Inc., Kyoto, Japan). Then, the purified DNA was sequenced with a Sequenase kit for ${ }^{35}$ S-dATP (United Biochemical, Inc.) by using the following primers: 5'-AGTTTGATCCTGGCTC-OH-3-' (same sequence as positions 10 to 25), 5'-GTGTTACTCACCCGT-OH-3' (complementary to positions 123 to 109), 5'-TACGGGAGG CAGCAG-OH-3' (same as positions 343 to 357 ), 5'-CTGCT GCCTCCCGTAG-OH-3' (complementary to positions 357 to 342), 5'-GTGCCAGCAGCCGCGG-OH-3' (same as positions 515 to 530), 5'-ACCGCGGCTGCTGGC-OH-3' (complementary to positions 531 to 516), 5'-TCTACGCATTTCA CC-OH-3' (complementary to positions 704 to 690), 5'-ATT AGATACCCTGGTA-OH-3' (same as positions 787 to 802), 5'-GTCAATTCCTTTGAGTTT-OH-3' (complementary to positions 924 to 907), 5'-GCAACGAGCGCAACCCOH-3 (same as positions 1099 to 1114), 5'-AGGGTTGCGCTCGT 'TG-OH-3' (complementary to positions 1115 to 1100 ), 5'-CC ATTGTAGCACGTGT-OH-3' (complementary to positions 1242 to 1227), 5'-TGTACACACCGCCCGT-OH-3' (same as positions 1391 to 1406), 5'-ACGGGCGGTGTGTAC-OH-3' (complementary to positions 1406 to 1392), 5'-GGCTACCT TGTTACGA-OH-3' (complementary to positions 1510 to 1495), and 5'-AAGGAGGTGATCCAGCC-OH-3' (complementary to positions 1541 to 1525 ). When the doublestranded DNAs were sequenced with Sequenase, to avoid the DNA polymerase reaction stopping at many positions on the sequence, we used the Mn buffer (45). The sequences at the $5^{\prime}$ end of $16 \mathrm{~S}$ rRNA were determined by the reverse transcriptase method (28).

Phylogenetic analysis. The sequences of the 16S rRNAs of members of the alpha subclass of the Proteobacteria, Agrobacterium tumefaciens DSM 30150 (51), Brucella abortus (10), Rochalimaea quintana (48), Bartonella bacilliformis (34), Rhodobacter capsulatus, Rhodospirillum rubrum, and Rhodopseudomonas acidophila were obtained from the EMBL and GenBank data bases for comparison. The genetic distances between the sequences were estimated by using the $K_{\text {nuc }}$ values (27). Then, a phylogenetic tree was constructed by the neighbor joining method (38) by using $E$. coli as the root organism. Deleted and unknown positions were eliminated for the comparison of sequences. Positions 70 to 100,181 to 219,447 to 487,1004 to 1036,1133 to 1141 , and 1446 to 1456 were eliminated from the comparison because the secondary structures of these regions differed between strains. The total number of nucleotides compared was 1,269. The topology of the reconstructed phylogenetic tree was evaluated by the bootstrap sampling method (12).

GenBank, EMBL, and DDBJ accession numbers. The sequences are available from GenBank, EMBL, and DDBJ (DNA Data Base of Japan, Mishima, Japan) under the following accession numbers: D01256 for NCPPB $2437^{\mathrm{T}}$, D01257 for IFO $13257^{\mathrm{T}}$, D01258 for NCPPB $3554,{ }^{\mathrm{T}}$ D01259 for IFO $13261^{\mathrm{T}}$, D01260 for K-Ag-3, D01261 for Ch-Ag-4, D01262 for NCPPB 1650, D01272 for ATCC $35423^{\mathrm{T}}$, D11343 for ATCC $43677^{\mathrm{T}}$, D13431 for IFO $15243^{\mathrm{T}}$, D01269 for IAM $12609^{\mathrm{T}}$, D01270 for ATCC $33669^{\mathrm{T}}$, D01265 for IAM $12611^{\mathrm{T}}$, D11344 for IFO $15247^{\mathrm{T}}$, D11345 for IAM $12608^{\mathrm{T}}$, D11342 for ORS $571^{\mathrm{T}}$, and D01266 for OK55.

\section{RESULTS}

The sequences which we determined are shown in Fig. 1. A matrix of the levels of sequence similarity for the representative strains belonging to the genera Agrobacterium, Rhizobium, Bradyrhizobium, and Azorhizobium and E. coli is shown in Table 1, and the phylogenetic tree derived from the sequence similarity values is shown in Fig. 2 . The levels of similarity among Agrobacterium species and Rhizobium species were more than $94 \%$. The strains belonging to the genera Agrobacterium and Rhizobium and Brucella abortus, Rochalimaea quintana, and Bartonella bacilliformis strains were clearly separated from Bradyrhizobium japonicum, Rhodopseudomonas acidophila, and Azorhizobium caulinodans. The levels of similarity between members of the Agrobacterium-Rhizobium branch and E. coli ranged from 77.1 to $82.6 \%$, and the levels of similarity between members of the Agrobacterium-Rhizobium branch and members of the Bradyrhizobium japonicum-Azorhizobium caulinodans branch ranged from 86.6 to $92.1 \%$. Agrobacterium species were not separated from Rhizobium species in this phylogenetic analysis (Fig. 2). The Agrobacterium and Rhizobium species and animal pathogens were divided into four clusters as follows: (i) a biovar 2 strain, Agrobacterium sp. strains K-Ag-3 and Ch-Ag-4, and strains of Rhizobium fredii, Rhizobium leguminosarum, Rhizobium meliloti, and Rhizobium tropici; (ii) biovar 1 and 3 strains, Agrobacterium rubi IFO $13261^{\mathrm{T}}$, Agrobacterium sp. strain NCPPB 1650, Rhizobium galegae ATCC $43677^{\mathrm{T}}$, and Rhizobium sp. strain OK55; (iii) Rhizobium loti and Rhizobium huakuii; and (iv) Brucella abortus, Rochalimaea quintana, and Bartonella bacilliformis. Biovar 2 strain IFO $13257^{\mathrm{T}}$ and strains K-Ag-3 and 


\begin{tabular}{|c|c|}
\hline R. leg & AACTTGAGAGTTTGATCCTGGCTCAGAACGAACGCTGGCGGCAGGCTT AACACATGCAAGTCGAGCGC \\
\hline R. lot & , \\
\hline nel & \\
\hline fre & 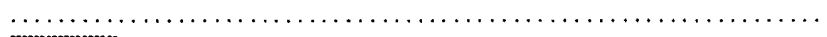 \\
\hline R. gal & 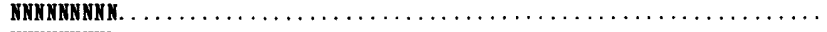 \\
\hline R. tro & NANMNNKKKK, . \\
\hline R. hua & 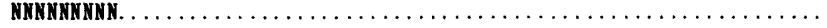 \\
\hline 0755 & 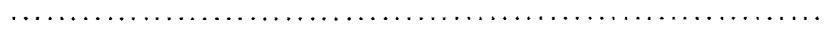 \\
\hline A.bio1 & 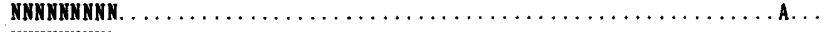 \\
\hline A. bio2 & 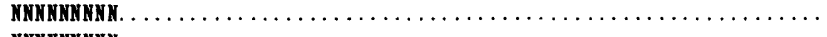 \\
\hline A.vit & NKKHKHWHA. $\ldots \ldots \ldots \ldots$ \\
\hline A. rub & 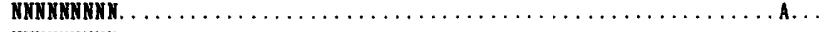 \\
\hline $\mathrm{X}-\mathrm{Ag}-\mathbf{3}$ & NHWHMNHWK. $\ldots \ldots \ldots \ldots \ldots \ldots \ldots \ldots \ldots \ldots \ldots \ldots$ \\
\hline Ch-Ag-4 & NNKNККНКK. \\
\hline NCPPB1650 & 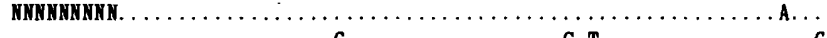 \\
\hline $\begin{array}{l}\text { B. jap } \\
\text { Azo. cau }\end{array}$ & 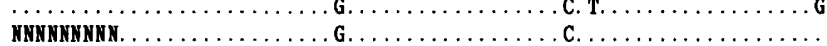 \\
\hline
\end{tabular}

\begin{tabular}{l|}
\hline CCCGCAAGGGG \\
CTCGCAAG \\
CCCGCAAGGGG \\
CCCGCAAGGNN \\
CTCGCAANNN \\
CCCGCAAGGNN \\
CCGCAAGGGG \\
CCCGCAAGGGG \\
CCCGCAAGGGG \\
CCCGCAANHNN \\
CTCGCAANNNN \\
TCCGCAANHNN \\
CCCGCAAGGGG \\
CCCGCAANHNN \\
CCCGCAAGGGG \\
GCGTAGCAATACGTC \\
CCAGCAATGGG \\
\hline
\end{tabular}

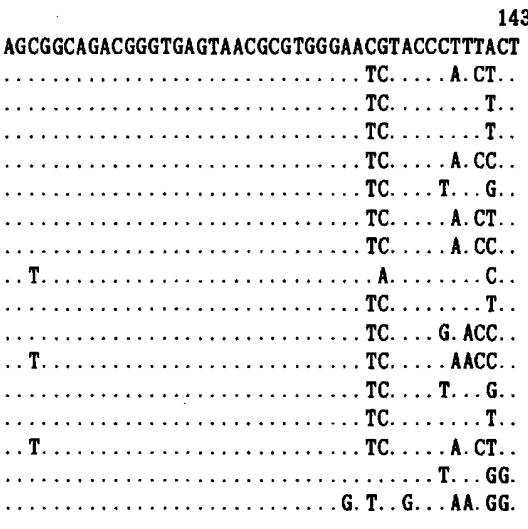

\begin{tabular}{|c|c|}
\hline leg & ACGGAATAACGCAGGGAAACTTGTGCTAATACCGTAT \\
\hline . $10 t$ & $\ldots \ldots$ C. . T.C...... G. A. . . . . \\
\hline R. nel & $\ldots \ldots \ldots \ldots$ \\
\hline R.fre & n. \\
\hline R. gal & $\ldots \ldots$ C. . T.C...... A. . . . T. . . \\
\hline R. tro & \\
\hline R. hua & 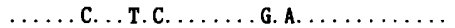 \\
\hline $0 \mathrm{~K} 55$ & 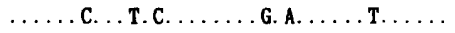 \\
\hline A. biol & 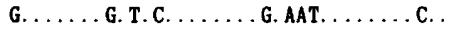 \\
\hline A.bio2 & $\ldots \ldots \ldots \ldots \ldots \ldots \ldots \ldots \ldots \ldots \ldots \ldots \ldots \ldots$ \\
\hline A.vit & $\ldots \ldots \ldots$ G. T.C. . . W G. AAT. . . . \\
\hline A. rub & 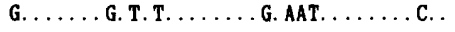 \\
\hline $\mathbf{R}-\mathbf{A g}-\mathbf{3}$ & 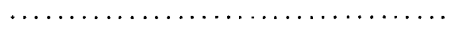 \\
\hline $\mathrm{Ch}-\mathrm{Ag}-4$ & 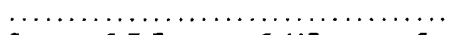 \\
\hline NCPPB1650 & G. . . . G. T. T. . . W G. AAT. . . . C. , \\
\hline B. jap & 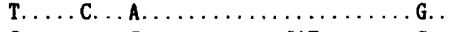 \\
\hline Azo. cau & G. $\ldots \ldots \ldots$ C. $\ldots \ldots \ldots$ GAT $\ldots \ldots$ C. \\
\hline
\end{tabular}

\begin{tabular}{|l|}
\hline GTGCCCTTTGGGGGAAAGATTTATC \\
ACGTCTTCGGGAGAAAGATTTATC \\
GAGCCCTTCGGGGGAAAGATTTATC \\
CAGCCCTTCGGGGGAAAGATTTATC \\
ACGCCCTTCGGGGGAAAGATTTATC \\
GTGTCCTTCGGGAGAAAGATTTATC \\
ACGTCCTTCGGGAGAAAGATTTATC \\
ACGCCCTTCGGGGGAAAGATTTATC \\
ACGCCCTACGGGGAAAGATTTATC \\
GTGTCCTTCGGGAGAAAGATTTATC \\
ACGCCCTTCGGGGAAAGATTTATC \\
ACGCCCTACGGGGGAAAGATTTATC \\
GTGTCCTTCGGGAGAAAGATTTATC \\
GTGTCCTTCGGGAGAAAGATTTATC \\
ACGCCCTACGGGGGAAAGATTTATC \\
AAGCCCTTACGGGGAAAGATTTATC \\
GTGCCCTTCGGGGGAAAGATTTATC
\end{tabular}

GGTAAAGGATCGGCCCGCGTTGGATTAGCTAGTTGGTGGGGTAAAGCCTACCAAGGCGACGAT

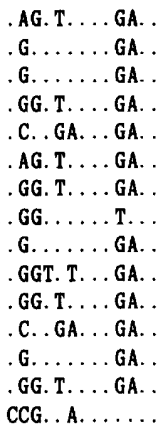

CCG. A. . . . . .

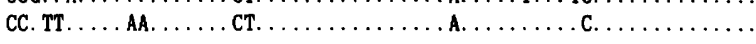

R.gal

R. tro

R. hua

0.855

A. biol

A. bio2

A.vit

A. rub

I-Ag-3

NCPPB1650

B. jap

Azo. cau

AG.

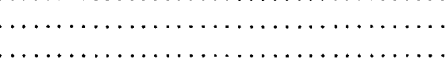

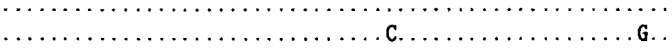

$\ldots \ldots \ldots \ldots \ldots \ldots \ldots \ldots \ldots \ldots \ldots \ldots \ldots \ldots \ldots \ldots \ldots \ldots \ldots \ldots$

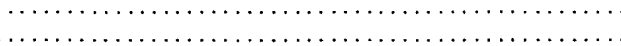

n.m. $\ldots \ldots \ldots \ldots \ldots \ldots$

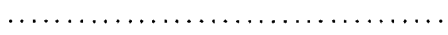

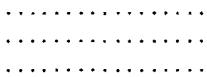

R. le

AAGGCCCTAGGGTTGTAAAGCTCTTTCACCGGA

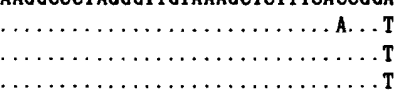

R. nel

R.fre

R.gal

R. tro

R. hua

$0 \mathrm{K55}$

A.bio1

A.bio2

A.vit

A. rub

.... T. T....A.

$\ldots \mathrm{T}$

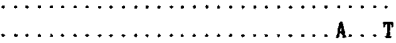

$\ldots$.

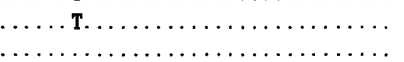

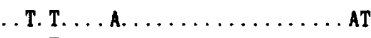

Ch-Ag-4

NCPPB1650 $\ldots \ldots$ T. .

B. jap

.... T...

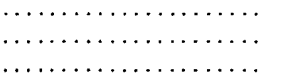

$\ldots \ldots$ T. $\ldots \ldots \ldots \ldots \ldots \ldots \ldots \ldots \ldots \ldots \ldots \ldots$ TGTGC. G

Azo. cau $\quad \ldots \ldots$ T. . . . . . . . T

GAAGATAATGACGGTA
GAAGATAATGACGGTA
GAAGATAATGACGGTA
GAAGATAATGACGGTA
GAAGATAATGACGGTA
GAAGATAATGACGGTA
GAAGATAATGACGGTA
GAAGATAATGACGGTA
GAAGATAATGACGGTA
GAAGATAATGACGGTA
GAAGATAATGACGGTA
GAAGATAATGACGGTA
GAAGATAATGACGGTA
GAAGATAATGACGGTA
GAAGATAATGACGGTA
GAAGATAATGACGGTA
GAAGATAATGACGGTA

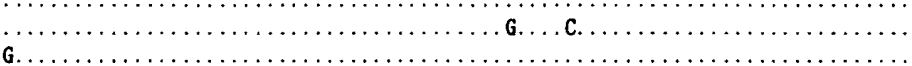

FIG. 1. Sequence alignment of $16 \mathrm{~S}$ rRNAs encoding DNAs for 17 strains belonging to the genera Rhizobium, Agrobacterium, Bradyrhizobium, and Azorhizobium. The sequences are aligned with the sequence of Rhizobium leguminosanum. Only the nucleotides that differ from those of Rhizobium leguminosarum are shown; identical nucleotides are indicated by dots, deletions are indicated by dashes, and the nucleotides that could not be identified are indicated by N. The numbers on the sequence of Rhizobium leguminosarum indicate positions from the $5^{\prime}$ end of $E$. coli $16 \mathrm{~S}$ rRNA. Positions 70 to 100,181 to 219,447 to 487,1004 to 1036,1133 to 1141 , and 1446 to 1456 ( $E$. coli numbering) are not aligned, and the sequences of these regions are enclosed in boxes. Abbreviations: R. leg, Rhizobium leguminosarum; R. lot, Rhizobium loti; R. mel, Rhizobium meliloti; R. fre, Rhizobium fredii; R. gal, Rhizobium galegae; R. tro, Rhizobium tropici; R. hua, Rhizobium huakuii; A. bio1, Agrobacterium biovar 1; A. bio2, Agrobacterium biovar 2; A. vit, Agrobacterium vitis; A. rub, Agrobacterium rubi; B. jap, Bradyrhizobium japonicum; Azo. cau, Azorhizobium caulinodans. 
R. 1 eg

R. lot

R. mel

R. fre

R. Bal

R. tro

R. hua

$0 \times 55$

A. biol

A. bio2

A.vit

A. rub

$\mathrm{X}-\mathrm{Ag}-3$

$\mathrm{Ch}-\mathrm{Ag}_{\mathrm{g}} 4$

MCPPB1650

B. jap

Azo. cau
TGGGCGTAAAGCGCACGTAGGCGGATCG

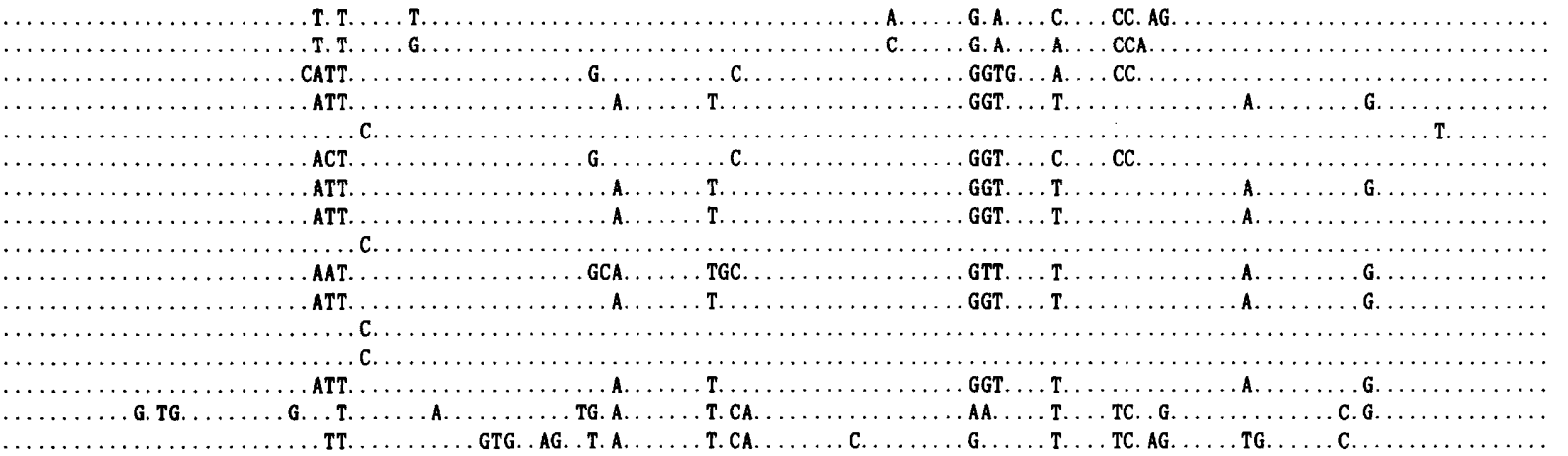

R. les

R. $\operatorname{lot}$

R. mel

R. fre

R. gal

R. tro

R. hua

$0 \times 55$

A. biol

A. bio2

A. vit

A. rub

$\mathrm{K}-\mathrm{Ag}-3$

$\mathrm{Ch}-\mathrm{Ag}-4$

NCPPB1650

B. jap

Azo. cau

R. 1 eg

R. lot

R. nel

R. fre

R. gal

R. tro

R. hua

$0 \mathrm{K55}$

A.biol

A. bio2

A.vit

A. rub

I-AB-3

Ch-Ag-4

ICPPB1650

B. jap

Azo. cau

AATTCGTAGATATTCGGAGgAACACCAGTGGCGAAGgCGGCTCACTGGTCCATTACTGACGCTGAGgTGCGAAAGCGTGgGGAGCAAACAGGATTAGATACCCTGGTAGTCCACGCCGTAAACGATGAAT

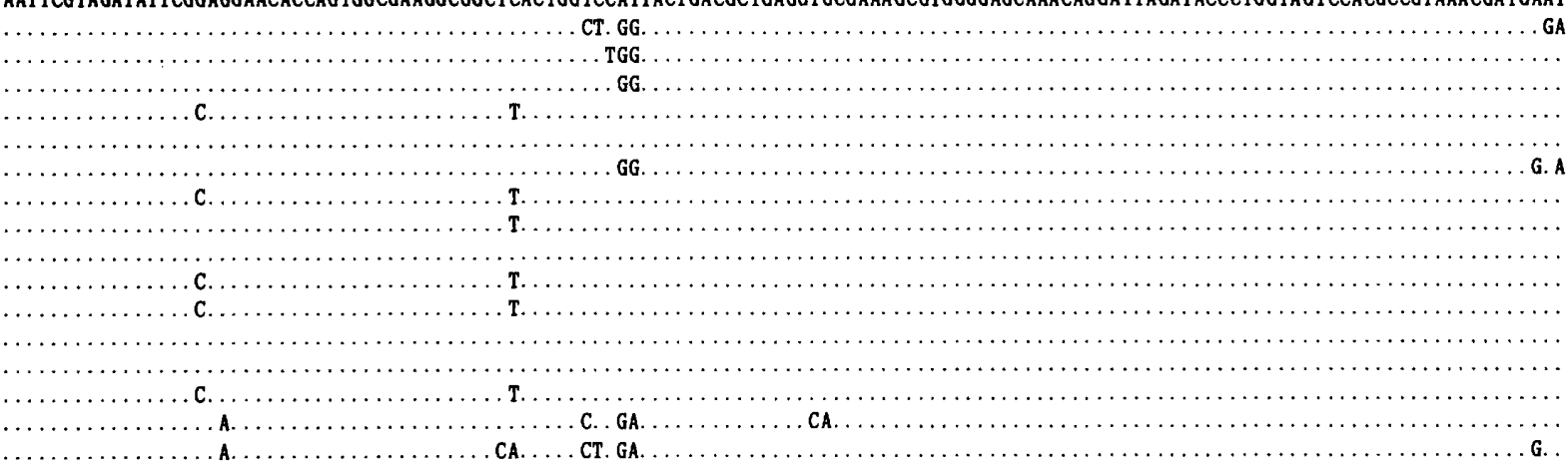
.

GTTAGCCGTCGgGCAGTATACTGTTCGgTGGCGCAGCTAACGCATTAAACATTCCGCCTGGGGAGTACGGTCGCAAGATTAAAACTCAAAGGAATTGACGGGGGCCCGCACAAGCGGTGGAGCATGTGGTT

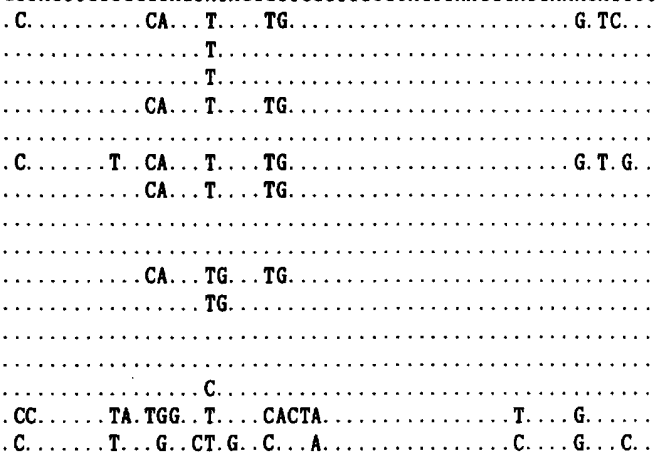

\begin{tabular}{|c|c|c|}
\hline R. 1 eg & TAATTCGAAGCAACGCGCAGAACCTTACCAGCCCTTGACATG-CCCGG & CTACTTGCAGAGATGCAAGGTTCTTCGGGGA \\
\hline R. lot & 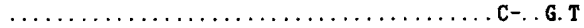 & CGCGGTTTCCAGAGATGGATACCTTCAGTTCGGCTGG \\
\hline R. nel & 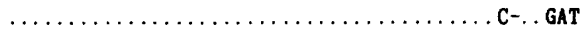 & CGCGGATACGAGAGATCGTATCCTTCAGTTCGGCTGG \\
\hline R.fre & $\ldots \ldots \ldots \ldots \ldots \ldots \ldots \ldots \ldots$ & CGCGGATACGAGAGATCGTATCCTTCAGTTCGGCTGG \\
\hline R. gal & $\ldots-\ldots \ldots$ & ACAGCTACAGAGATGTAGTGNNNNNTTCGGGGA \\
\hline R. tro & $\ldots \ldots \ldots \ldots \ldots \ldots \ldots \ldots \ldots \ldots$ C-. TGT. & TTACCTCTAGAGATAGGGGGTCCACTTCGGTGG \\
\hline R. hua & $\ldots \ldots \ldots \ldots \ldots \ldots \ldots \ldots \ldots$ T. $\ldots \ldots \ldots$ C- G.T & CGCGGTTTCCAGAGATGGATTCCTTTCAGTTCGGCTGG \\
\hline 0855 & $\ldots \ldots \ldots \ldots \ldots \ldots \ldots \ldots \ldots \ldots \ldots \ldots \ldots-\ldots \ldots$ & CCAGCCACAGAGATGTGGGGTTTTCGGGGA \\
\hline A. biol & $\ldots \ldots \ldots \ldots \ldots \ldots \ldots \ldots \ldots \ldots \ldots \ldots$ T. $\ldots \ldots \ldots$ T-GG. & TTTGGGCAGTGGAGACATTGTCCTTCAGTTAGGCTGG \\
\hline A.bio2 & $\ldots \ldots \ldots \ldots \ldots \ldots \ldots \ldots \ldots \ldots \ldots \ldots$ C-TGT. & TTACCCGTAGAGATATGGGGTCCACTTCGGTGG \\
\hline A.vit & $\ldots \ldots \ldots \ldots \ldots \ldots \ldots \ldots \ldots$ T. TGT. & ACCGCACGGAGACGTGGTTTTTCCTTTCGGGGA \\
\hline A. rub & $\ldots \ldots \ldots \ldots \ldots \ldots \ldots \ldots$ T. $\ldots \ldots$ T- GG. . & TTTGGGCAGTGGAGACATTGTCCTTCAGTTAGGCTGG \\
\hline $\mathrm{I}-\mathrm{Ag}-\mathbf{3}$ & ....C-.TGT. & TTACCTCTAGAGATAGGGGGTCCACTTCGGTGG \\
\hline $\mathrm{Ch}-\mathrm{Ag}-4$ & ... C-. TGT. & TTACCCGTAGAGATATGGGGTCCACTTCGGTGG \\
\hline NCPPB 1650 & $\ldots \ldots \ldots \ldots \ldots \ldots \ldots \ldots \ldots \ldots \ldots$ T. $\ldots \ldots$, T-.GG. . & TTTGGGCAGTGGAGACATTGTCCTTCAGTTAGGCTGG \\
\hline B. jap & $\ldots \ldots \ldots$ с $\ldots \ldots \ldots \ldots \ldots \ldots \ldots \ldots \ldots \ldots$ T. А. . & ACCGGTCGCAGAGATGTGACCTTCTCTTCGGAG \\
\hline Azo. cau & $\ldots \ldots \ldots \ldots \ldots \ldots \ldots \ldots \ldots \ldots \ldots$ T. $\ldots \ldots$, G. A. . & ACGACTTCCGGAGACGGATTTCTTCCAGCAATGGA \\
\hline
\end{tabular}

ACA. - G.

. . CCAG-A.

. GCA. . -G.

. GCA. - -G.

CCAG-A.

T. . G.

FIG. 1-Continued.

Ch-Ag-4 were close relatives of Rhizobium leguminosarum and Rhizobium tropici. Rhizobium tropici and strain K-Ag-3 differed by two nucleotides. Rhizobium sp. strain OK55 was closely related to Rhizobium galegae. The sequence of
Agrobacterium tumefaciens DSM 30150 reported by Yang et al. (51) was similar to the sequences of Agrobacterium strains, and strain DSM 30150 was a close relative of biovar 1 (level of similarity, 99.2\%). The two sequences were 


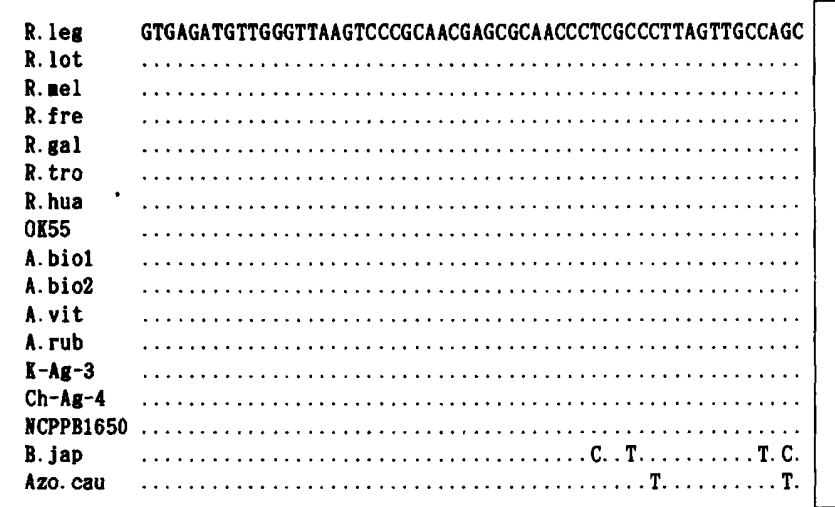

\begin{tabular}{|l|}
\hline ATTCAGTT \\
ATTCAGTT \\
ATTCAGTT \\
ATTTAGTT \\
ATTCAGTT \\
ATTCAGTT \\
ATTCAGTT \\
ATTCAGTT \\
ATTTAGTT \\
ATTCAGTT \\
ATTCAGTT \\
ATTTNGTT \\
ATTTAGTT \\
ATTTAGTT \\
ATTTGGTT \\
ATTTAGTT \\
ATTCAGTT \\
\hline
\end{tabular}

1202

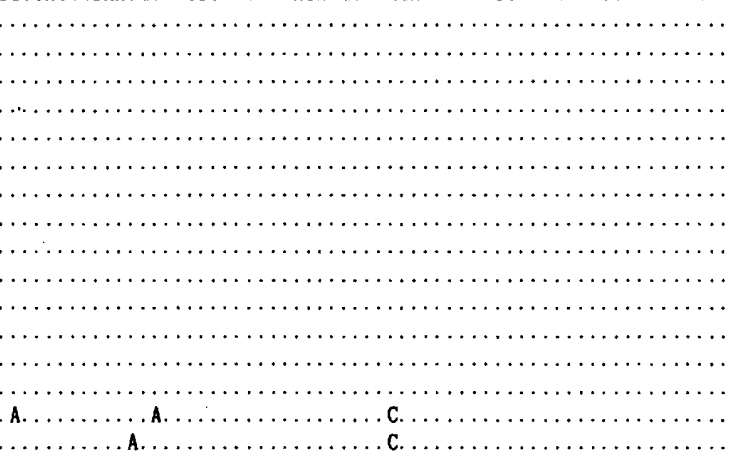

1333

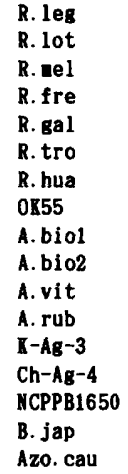

CATGGCCCTTACGGGCTGGGCTACACACGTGCTACAATGGTGGTGACAGTGGGCAGCGAGCACGCGAGTGTGAGCTAATCTCCAAAAGCCATCTCAGTTCGGATTGCACTCTGCAACTCGAGTGCATGA

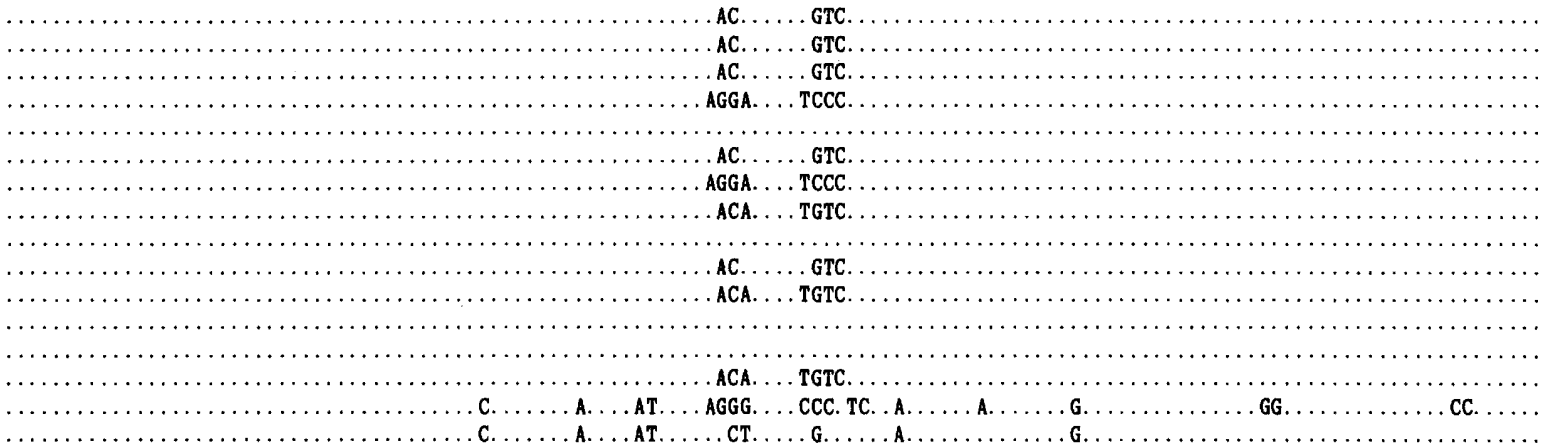

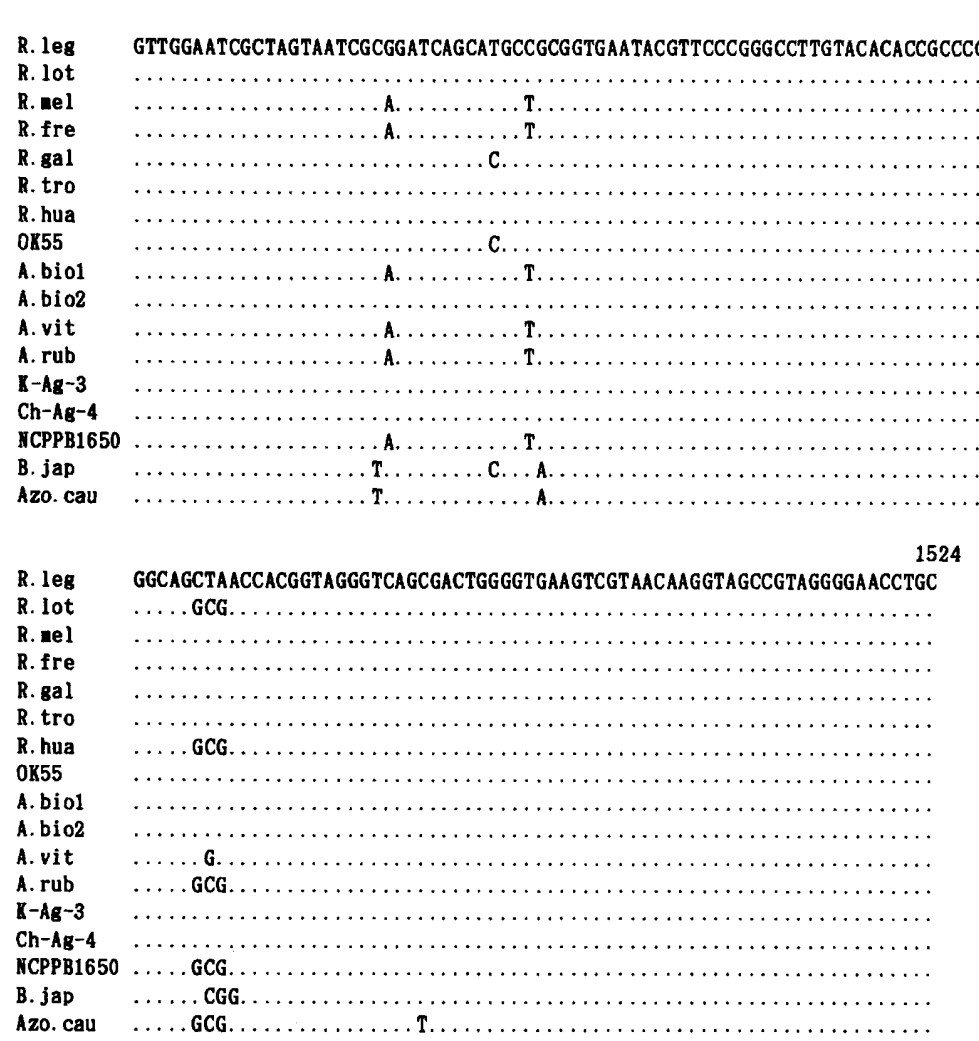

FIG. 1--Continued.

different at positions 131, 132, 137, 139, 140, 224, 226, 230, and 231.

A bootstrap sampling analysis was carried out to estimate the confidence limits of the reconstructed phylogenetic tree.
The branch containing animal-pathogenic species (Bartonella, Brucella, and Rochalimaea species) was separated with a confidence limit of $40 \%$ from the cluster containing all of the species of the genera Rhizobium and Agrobacterium. The 
TABLE 1. Similarity matrix for 16S rRNA sequences of Agrobacterium and Rhizobium species and their relatives

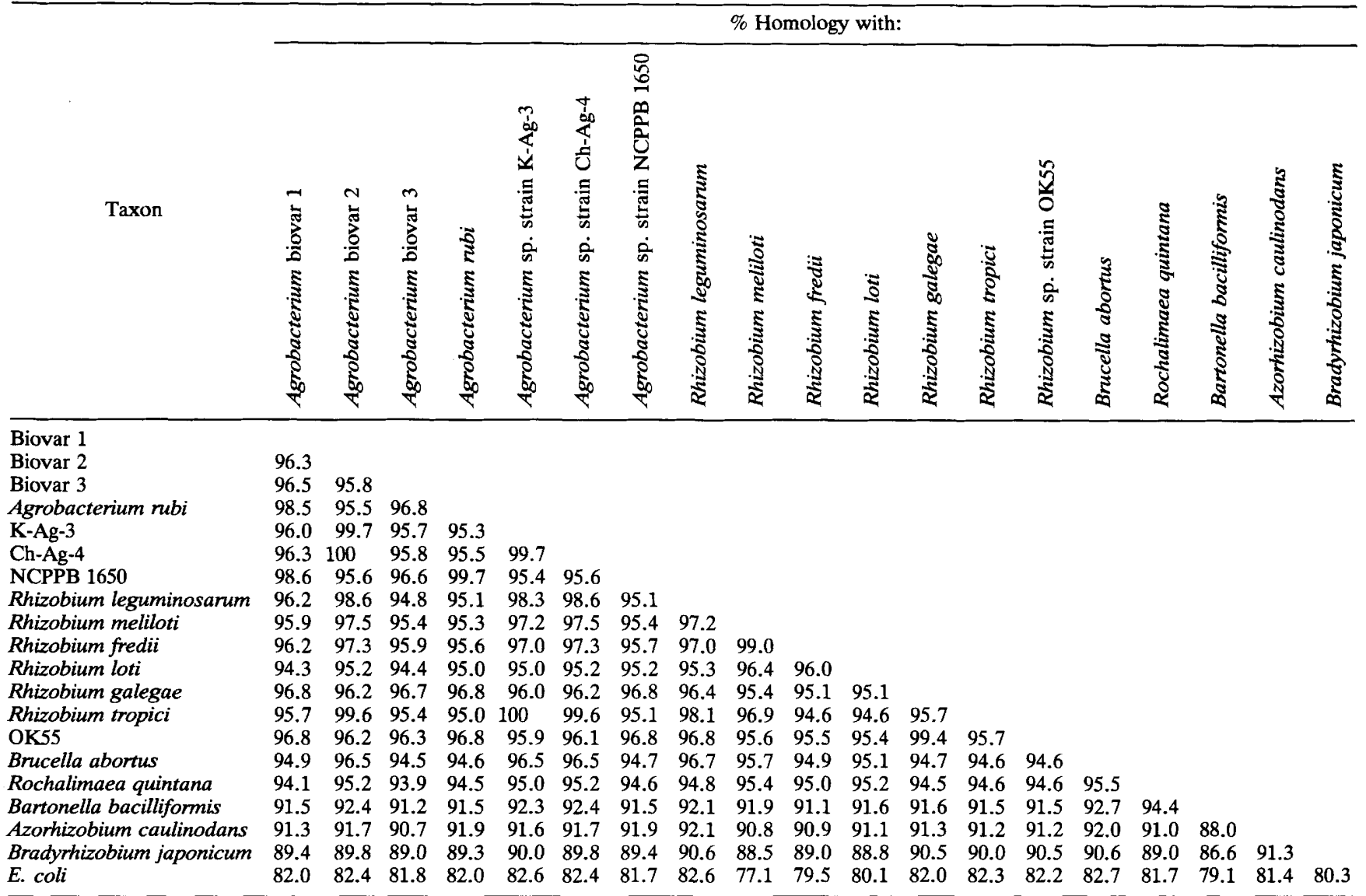

low level of confidence was attributed to the presence of Rhizobium loti and Rhizobium huakuii because these species were situated at an intermediate position between the cluster containing animal pathogens and the cluster containing the other Rhizobium and Agrobacterium species. A bootstrap sampling analysis performed without Rhizobium loti and Rhizobium huakuii revealed a $70 \%$ level of confidence for the branching between animal pathogens and the genera Rhizobium and Agrobacterium.

\section{DISCUSSION}

The genus Agrobacterium was established by Conn (4) in 1942 for gram-negative, aerobic, peritrichous bacteria which were frequently isolated from soil. The strain studied by Conn was not phytopathogenic. However, he grouped the strain together with phytopathogenic strains which induce tumor or root proliferation because of its close morphological and physiological relationship. When the genus Agrobacterium was established, Conn designated the tumor-causing organism Agrobacterium tumefaciens the type species and named strains causing hairy root Agrobacterium rhizogenes and the nonphytopathogenic strains Agrobacterium radiobacter. Later, De Ley and colleagues recognized the existence of several different groups regardless of the phytopathogenicity in the genus. Two of the major groups were designated biotypes 1 and 2 by Keane et al. (21), and a third group, biotype 3 , was recognized by Panagopoulos and Psallidas (36) and Kerr and Panagopoulos (24). Later, the biotypes were changed to biovars $(26,32)$. In the meantime, other researchers who discovered megaplasmids showed that the megaplasmids induced tumors or hairy roots $(22,23$, $30,33,46,49,52)$. These plasmids are believed to be transferable among Agrobacterium strains (22, 23, 30). Conn's system has been criticized by many researchers $(6$, $17-19,35,39)$. The taxonomic organization of the genus should be changed.

As mentioned above, most of the pathogenicity genes in Agrobacterium species are encoded on megaplasmids, and many strains that do not harboring plasmids have been found. Therefore, it is plausible to eliminate pathogenicity from the definition of the genus Agrobacterium and from the characteristics used to differentiate Agrobacterium species. Our data concerning the 16S rRNA sequences of Agrobacterium species and Rhizobium species support this change and supply information required for revision of the classification of Agrobacterium species. De Smedt and De Ley (9) and Jarvis et al. (19) obtained similar results, based on rRNA-DNA homology data, for the relationship between the genera Rhizobium and Agrobacterium.

De Ley et al. (7) and Jarvis et al. (19) observed that the genera Brucella, Phyllobacterium, and Mycoplana were phylogenetically closely related to the genera Agrobacterium and Rhizobium on the basis of rRNA cistron similarity data, but separated the genus Brucella from the genera Agrobacterium and Rhizobium (19, 24). Analyses of $16 \mathrm{~S}$ rRNA sequences also showed that Rochalimaea quintana and Bartonella bacilliformis were close relatives of the genus 


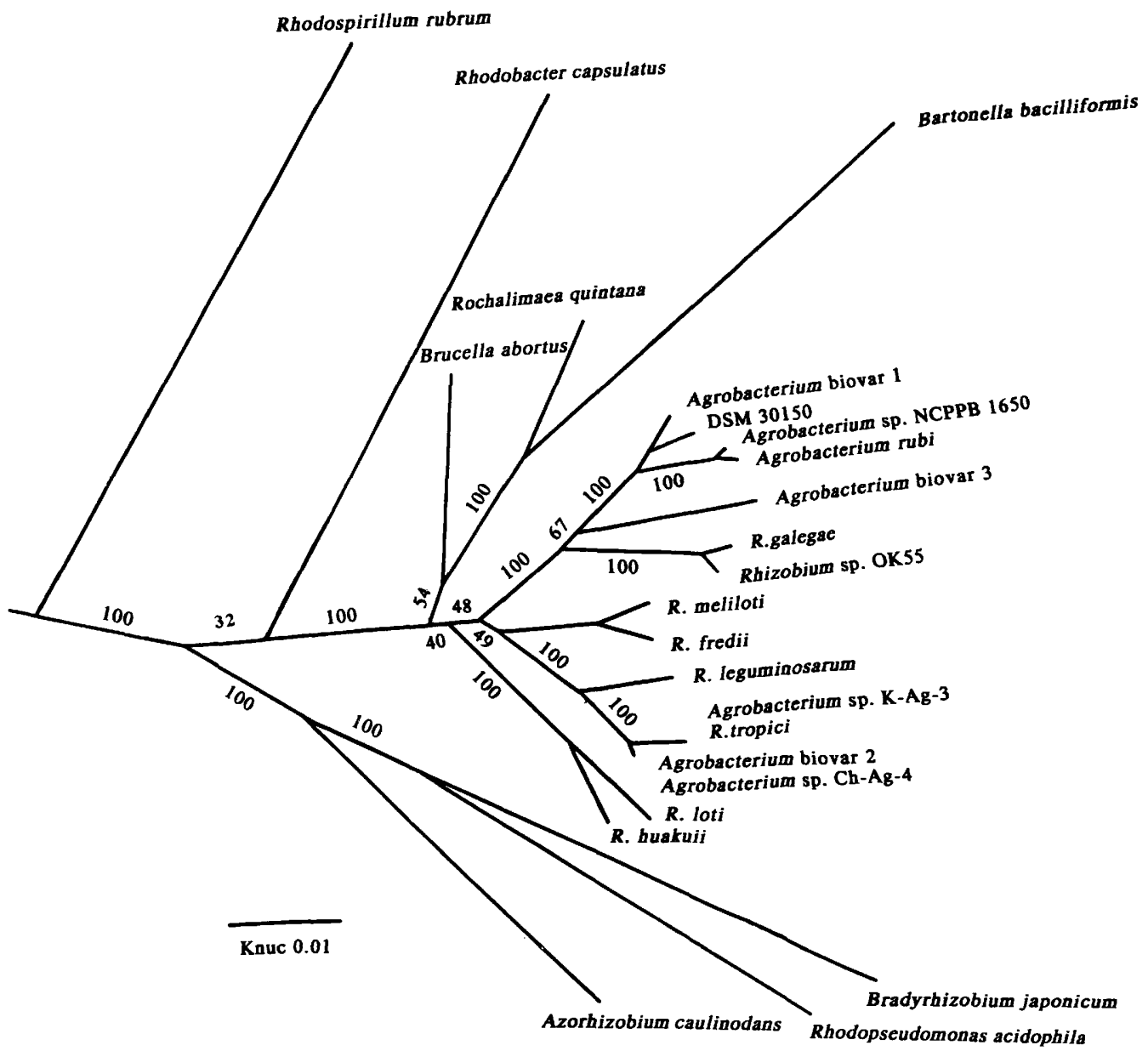

FIG. 2. Phylogenetic tree derived from the whole $16 \mathrm{~S}$ rRNA sequences for members of the genera Agrobacterium and Rhizobium and their relatives. E. coli was used as the root organism. Positions 70 to 100,181 to 219,447 to 487,1004 to 1036,1133 to 1141 , and 1445 to $1456(E$. coli numbering) were not used for the comparison because the secondary structures of these regions varied among the strains compared. The value on each branch is the estimated confidence limit (expressed as a percentage) for the position of the branch as determined by bootstrap analysis.

Agrobacterium (34) and showed that Brucella abortus, Rochalimaea quintana, and Bartonella bacilliformis formed a phylogenetic cluster distinct from the genus Agrobacterium (34). It is necessary to clarify the boundaries between the genera Agrobacterium, Rhizobium, Brucella, Rochalimaea, Bartonella, Mycoplana, and Phyllobacterium. Our data for the genera Agrobacterium and Rhizobium suggested that these two genera may be combined because they are distinct from the other five genera on the basis of their 16S rRNA sequences, morphology, and plant root association. However, bootstrap analysis gave relatively low levels of confidence (40 and $70 \%$ without Rhizobium loti and Rhizobium huakuii) for the separation between the animal pathogens and the plant root-associated species. On the basis of the values obtained in the bootstrap analysis it is not certain that the Agrobacterium-Rhizobium branch is monophyletic. The seven genera apparently form a cluster of $16 \mathrm{~S}$ rRNA sequences and show rRNA cistron similarities; however, the data are not sufficient to conclusively separate the cluster into subgroups. The phylogenetic tree is not reliable enough for taxonomic conclusions to be drawn, and it may allow controversial opinions. Therefore, at present we should not rush to combine Agrobacterium and Rhizobium species in one genus.
Another problem is found in the taxonomic treatment of biovars 1 and 2 . The biovar 1 and 2 strains form homogeneous taxa on the basis of their phenotypes $(18,21,24,25$, $39,40,50)$ and chemotaxonomic characteristics $(6,42)$, respectively. Sawada et al. (41) reported that the two biovars are clearly distinguished by their signature 16S rRNA sequences. Below we propose revised descriptions for Agrobacterium radiobacter and Agrobacterium rhizogenes. In our proposal the biovar 1 strains are assigned to Agrobacterium radiobacter, and the biovar 2 strains are assigned to Agrobacterium rhizogenes. Although the biovar 1 strains exhibit heterogeneity in DNA-DNA relatedness $(6,26)$, the difference values are on the border of the values required to separate species (20). Additional studies will be necessary for further division of biovar 1 , and in our proposal the biovar 1 strains are included in a single species. Agrobacterium tumefaciens should be rejected for the following reasons. The type strain of Agrobacterium radiobacter is a biovar 1 strain, and biovar 1 also contains the type strain of Agrobacterium tumefaciens. The level of total DNA-DNA relatedness between type strain IAM 12048 of Agrobacterium radiobacter and type strain NCPPB 2437 of Agrobacterium tumefaciens was $87 \%$ in our study (unpublished data) and $80 \%$ in the study of Ophel and Kerr (35). De Ley et al. 
(8) reported that the thermal stability $\left[T_{m(e)}\right]$ of DNA-DNA hybrids between the two strains was $1.2^{\circ} \mathrm{C}$ lower than the reference $T_{m(e)}$, which corresponded to a DNA-DNA relatedness value of more than $80 \%$. These values are high enough to place the two strains in the same species $(20,47)$. Therefore, the taxon consisting of the biovar 1 strains, which should be a single species, contains the type strains of two species, Agrobacterium tumefaciens and Agrobacterium radiobacter. According to the International Code of Nomenclature of Bacteria (29), one of those species should be rejected. According to Rule 38, the species established earlier should be maintained. Agrobacterium tumefaciens was established originally in 1907 by Smith and Townsend (43) as Bacterium tumefaciens, and Agrobacterium radiobacter was established originally in 1902 by Beijerinck and van Delden (2) as Bacillus radiobacter. Therefore, the species epithet radiobacter should be maintained for the biovar 1 strains. Consequently, the description of the genus Agrobacterium is revised. The type strain of Agrobacterium rhizogenes is included in biovar 2; therefore, the biovar 2 strains are assigned to Agrobacterium rhizogenes.

In this study taxonomic status was not given to unclassified strains K-Ag-3, Ch-Ag-4, and NCPPB 1650. These strains are different from Agrobacterium radiobacter, Agrobacterium rhizogenes, Agrobacterium rubi, and Agrobacterium vitis in their phenotypic characteristics (39) and DNADNA relatedness levels (unpublished data). Therefore, it will be necessary to establish several new species for these strains.

The diagnostic key characteristics reported by some authors $(39,40,42)$ are included below in the revised descriptions of Agrobacterium radiobacter and Agrobacterium rhizogenes.

Revised description of the genus Agrobacterium Conn 1942. Cells are normally rod shaped. Nonsporeforming. Gram negative. Motile by means of one to six peritrichous flagella. Aerobic, possessing a respiratory type of metabolism with oxygen as the terminal electron acceptor. Some strains are capable of anaerobic respiration in the presence of nitrate. Optimum temperature, 25 to $28^{\circ} \mathrm{C}$. Optimum $\mathrm{pH}, 6$ to 7 . Colonies are circular, convex, smooth, and nonpigmented to light beige. Growth on carbohydrate-containing media is usually accompanied by copious extracellular polysaccharide slime. Catalase and urease positive. Some strains produce 3-ketoglycosides. Chemoorganotrophic, utilizing a wide range of carbohydrates, organic acids, and amino acids as carbon sources, but not cellulose. Produces an acid reaction in mineral salts media containing D-glucose, D-galactose, and other carbohydrates. Some strains grow with ammonium salts and nitrates as nitrogen sources, and some strains require additional growth factors. Some strains of the genus invade the crowns, roots, and stems of a large variety of dicotyledonous plants and some gymnospermous plants via wounds, causing the transformation of the plant cells into autonomously proliferating tumor cells. The induced plant diseases are commonly known as crown gall, hairy root, or cane gall. Tumor induction by agrobacteria is correlated with the presence of a large $\mathrm{Ti}$ plasmid, and hairy root induction is correlated with the presence of a large $\mathrm{Ri}$ plasmid. The $\mathrm{G}+\mathrm{C}$ contents of the DNAs range from 57 to $63 \mathrm{~mol} \%$. Ubiquinone is used in the respiratory chain, and the major form is Q-10.

Type species: Agrobacterium radiobacter.

Revised description of Agrobacterium radiobacter Beijerinck and van Delden 1902 (Conn 1942). The morphology of the cells and colonies is the same as the morphology described above for the genus. Strains do not require any growth factors and grow in simple mineral salts medium (11) containing utilizable carbohydrate. Most of the strains utilize citrate but not L-tyrosine. Does not grow on New-Kerr medium (32). Acid is produced from dulcitol and $\alpha$-methylD-glucoside in Ayers-Rupp-Johnson synthetic medium (1) containing $0.02 \%$ yeast extract (Difco). 3-Ketolactose is produced from lactose. Grows at $35^{\circ} \mathrm{C}$. The arginine dihydrolase test is positive in Thornley's medium (5). A pellicle is produced in ferric ammonium citrate solution (32).

A large tumor-inducing plasmid (Ti) or a hairy rootinducing plasmid ( $\mathrm{Ri}$ ) is detected in many strains. Isolated from soil, plant rhizospheres, young gall tissues, and hairy roots of many plant species.

The $\mathrm{G}+\mathrm{C}$ content of the DNA is 57 to $63 \mathrm{~mol} \%$.

Type strain: ATCC 19358 (= NCIB $9042=$ DSM $30147=$ IFO 13532 = IAM 12048).

Revised description of Agrobacterium rhizogenes Riker, Banfield, Wright, Keitt, and Sagen 1930 (Conn 1942). The morphology of the cells and colonies is the same as the morphology described above for the genus. Strains require growth factors and do not grow in simple mineral salts medium (11). Citrate and L-tyrosine are utilized. Grows on New-Kerr medium (32). Acid is produced from dulcitol and $\alpha$-methyl-D-glucoside in the Ayers-Rupp-Johnson synthetic medium (1) containing $0.02 \%$ yeast extract (Difco). 3-Ketolactose is not produced from lactose. Does not grow at $35^{\circ} \mathrm{C}$. The arginine dihydrolase test is negative in Thornley's medium (5). No pellicle is produced in ferric ammonium citrate solution (32).

A large tumor-inducing plasmid (Ti) or a hairy rootinducing plasmid $(\mathrm{Ri})$ is detected in many strains. Isolated from soil, plant rhizospheres, young gall tissues, and hairy roots of many plant species.

The $\mathrm{G}+\mathrm{C}$ content of the DNA is 57 to $63 \mathrm{~mol} \%$.

Type strain: ATCC 11325 (= DSM 30148 = IFO 13257).

\section{REFERENCES}

1. Ayers, S. H., P. Rupp, and W. T. Johnson. 1919. A study of the alkali-forming bacteria in milk. Bulletin 782. U. S. Department of Agriculture, Washington, D.C.

2. Beijerinck, M. W., and A. van Delden. 1902. Über die Assimilation des freien Stickstoffs durch Bakterien. Zentralbl. Bakteriol. Parasitenkd. Infektionskr. Hyg. Abt. 2 9:3-43.

3. Burr, T. J., A. L. Bishop, B. H. Katz, L. M. Blanchard, and C. Bazzi. 1987. A root specific decay of grapevine caused by Agrobacterium tumefaciens and $A$. radiobacter biovar 3. Phytopathology 77:1424-1427.

4. Conn, H. J. 1942. Validity of the genus Alcaligenes. J. Bacteriol. 44:353-360.

5. Cowan, S. T. 1974. Cowan \& Steel's manual for the identification of medical bacteria, 2nd ed. Cambridge University Press, Cambridge.

6. De Ley, J. 1974. Phylogeny of procaryotes. Taxon 23:291-300.

7. De Ley, J., W. Mannheim, P. Segers, A. Lievens, M. Denijn, M. Vanhoucke, and M. Gillis. 1987. Ribosomal ribonucleic acid cistron similarities and taxonomic neighborhood of Brucella and CDC group Vd. Int. J. Syst. Bacteriol. 37:35-42.

8. De Ley, J., R. Tijtgat, J. De Smedt, and M. Michiels. 1973. Thermal stability of DNA:DNA hybrids within the genus Agrobacterium. J. Gen. Microbiol. 78:241-252.

9. De Smedt, J., and J. De Ley. 1977. Intra- and intergeneric similarities of Agrobacterium ribosomal ribonucleic acid cistrons. Int. J. Syst. Bacteriol. 27:222-240. 
10. Dorsch, M., E. Moreno, and E. Stackebrandt. 1989. Nucleotide sequence of the 16S rRNA from Brucella abortus. Nucleic Acids Res. 17:1765.

11. Dye, D. W. 1968. A taxonomic study of the genus Erwinia. I. The "amylovora" group. N. Z. J. Sci. 11:590-607.

12. Felsenstein, J. 1985. Confidence limits on phylogenies: an approach using the bootstrap. Evolution 39:783-791.

13. Freney, J., L. D. Gruer, N. Bornstein, M. Kiredjian, I. Guilvout, M. N. Letouzey, C. Combe, and J. Fleurette. 1985. Septicemia caused by Agrobacterium sp. J. Clin. Microbiol. 22:683-685.

14. Graham, P. H. 1964. The application of computer techniques to the taxonomy of the root-nodule bacteria of legumes. J. Gen. Microbiol. 35:511-517.

15. Heberlein, G. T., J. De Ley, and R. Tijtgat. 1967. Deoxyribonucleic acid homology and taxonomy of Agrobacterium, Rhizobium, and Chromobacterium. J. Bacteriol. 94:116-124.

16. Hildebrand, E. M. 1940. Cane gall of brambles caused by Phytomonas rubi n. sp. J. Agric. Res. 61:685-696.

17. Holmes, B. 1988. Taxonomy of Agrobacterium. Acta Hortic. (The Hague) 225:47-52.

18. Holmes, B., and P. Roberts. 1981. The classification, identification and nomenclature of agrobacteria. Incorporating revised descriptions for each of Agrobacterium tumefaciens (Smith \& Townsend) Conn 1942, Agrobacterium rhizogenes (Riker et al.) Conn 1942, and Agrobacterium rubi (Hildebrand) Starr \& Weiss 1943. J. Appl. Bacteriol. 50:443-467.

19. Jarvis, B. D. W., M. Gillis, and J. De Ley. 1986. Intra- and intergeneric similarities between the ribosomal ribonucleic acid cistrons of Rhizobium and Bradyrhizobium species and some related bacteria. Int. J. Syst. Bacteriol. 36:129-138.

20. Johnson, J. L. 1984. Bacterial classification. III. Nucleic acids in bacterial classification, p. 8-11. In N. R. Krieg and J. G. Holt (ed.), Bergey's manual of systematic bacteriology, vol. 1. The Williams \& Wilkins Co., Baltimore.

21. Keane, P. J., A. Kerr, and P. B. New. 1970. Crown gall of stone fruit. Aust. J. Biol. Sci. 23:585-595.

22. Kerr, A. 1969. Transfer of virulence between isolates of Agrobacterium. Nature (London) 223:1175-1176.

23. Kerr, A. 1971. Acquisition of virulence by non-pathogenic isolates of Agrobacterium radiobacter. Physiol. Plant Pathol. 1:241-246.

24. Kerr, A., and C. G. Panagopoulos. 1977. Biotypes of Agrobacterium radiobacter var. tumefaciens and their biological control. Phytopathol. Z. 90:172-179.

25. Kersters, K., J. De Ley, P. H. A. Sneath, and M. Sackin. 1973. Numerical taxonomic analysis of Agrobacterium. J. Gen. Microbiol. 78:227-239.

26. Kersters, K., and J. De Ley. 1984. Genus III. Agrobacterium Conn 1942, p. 244-254. In N. R. Krieg and J. G. Holt (ed.), Bergey's manual of systematic bacteriology, vol. 1. The Williams \& Wilkins Co., Baltimore.

27. Kimura, M. 1980 . A simple method for estimating evolutionary rates of base substitutions through comparative studies of nucleotide sequences. J. Mol. Evol. 16:111-120.

28. Lane, D. J., B. Pace, G. J. Olsen, D. A. Stahl, M. L. Sogin, and N. R. Pace. 1985. Rapid determination of 16S ribosomal RNA sequences for phylogenetic analyses. Proc. Natl. Acad. Sci. USA 82:6955-6959.

29. Lapage, S. P., P. H. A. Sneath, E. F. Lessel, V. B. D. Skerman, H. P. R. Seeliger, and W. A. Clark (ed.). 1992. International code of nomenclature of bacteria, 1990 revision. American Society for Microbiology, Washington, D.C.

30. Larebeke, N. V., C. Genetello, J. Schell, R. A. Schilperoort, A. K. Hermans, J. P. Hernalsteens, and M. V. Montagu. 1975. Acquisition of tumour-inducing ability by non-oncogenic agrobacteria as a result of plasmid transfer. Nature (London) 255: 742-743.

31. Miyashita, K. 1987. Deoxyribonucleic acid homology among strains of soybean-nodulating bacteria. Soil. Sci. Plant Nutr. 33:639-643.
32. Moore, L. W., A. Anderson, and C. I. Kado. 1980. III. Gramnegative bacteria A, Agrobacterium, p. 17-25. In N. W. Schaad (ed.), Laboratory guide for identification of plant pathogenic bacteria. American Phytopathological Society, St. Paul, Minn.

33. Moore, L. W., G. Warren, and G. Strobel. 1979. Involvement of a plasmid in the hairy root disease of plants caused by Agrobacterium rhizogenes. Plasmid 2:617-626.

34. O'Connor, S. P., M. Dorsch, A. G. Steigerwalt, D. J. Brenner, and E. Stackebrandt. 1991. 16S rRNA sequences of Bartonella bacilliformis and cat scratch disease bacillus reveal phylogenetic relationships with the alpha-2 subgroup of the class Proteobacteria. J. Clin. Microbiol. 29:2144-2150.

35. Ophel, K., and A. Kerr. 1990. Agrobacterium vitis sp. nov. for strains of Agrobacterium biovar 3 from grapevines. Int. J. Syst. Bacteriol. 40:236-241.

36. Panagopoulos, C. G., and P. G. Psallidas. 1973. Characteristics of Greek isolates of Agrobacterium tumefaciens (E. F. Smith \& Townsend) Conn. J. Appl. Bacteriol. 36:233-240.

37. Saiki, R. K., D. H. Gelfand, S. Stoffe, S. J. Scharf, R. Higuchi, G. T. Horn, K. B. Mullis, and H. A. Erlich. 1988. Primerdirected enzymatic amplification of DNA with a thermostable DNA polymerase. Science 239:487-491.

38. Saitou, N., and M. Nei. 1987. The neighbor-joining method: a new method for reconstructing phylogenetic trees. Mol. Biol. Evol. 4:406-425.

39. Sawada, H., and H. Ieki. 1992. Phenotypic characteristics of the genus Agrobacterium. Ann. Phytopathol. Soc. Jpn. 58:37-45.

40. Sawada, H., H. Ieki, and Y. Takikawa. 1990. Identification of grapevine crown gall bacteria isolated in Japan. Ann. Phytopathol. Soc. Jpn. 56:199-206.

41. Sawada, H., H. Oyaizu, S. Matsumoto, and H. Ieki. 1992. Differentiation of Agrobacterium taxa based on partial sequences of 16S rRNA. Ann. Phytopathol. Soc. Jpn. 58:761-765.

42. Sawada, H., Y. Takikawa, and H. Ieki. 1992. Fatty acid methyl ester profiles of the genus Agrobacterium. Ann. Phytopathol. Soc. Jpn. 58:46-51.

43. Smith, E. F., and C. O. Townsend. 1907. A plant tumor of bacterial origin. Science 25:671-673.

44. Starr, M. P., and J. E. Weiss. 1943. Growth of phytopathogenic bacteria in a synthetic asparagine medium. Phytopathology 33:314-318.

45. Tabor, S., and C. C. Richardson. 1989. Effect of manganese ions on the incorporation of dideoxynucleotides by bacteriophage T7 DNA polymerase and Escherichia coli DNA polymerase. Proc. Natl. Acad. Sci. USA 86:4076-4080.

46. Watson, B., T. C. Currier, M. P. Gordon, M. Chilton, and E. W. Nester. 1975. Plasmid required for virulence of Agrobacterium tumefaciens. J. Bacteriol. 123:255-264.

47. Wayne, L. G., D. J. Brenner, R. R. Colwell, P. A. D. Grimont, O. Kandler, M. I. Krichevsky, L. H. Moore, W. E. C. Moore, R. G. E. Murray, E. Stackebrandt, M. P. Starr, and H. G. Trüper. 1987. Report of the Ad Hoc Committee on Reconciliation of Approaches to Bacterial Systematics. Int. J. Syst. Bacteriol. 37:463-464.

48. Weisburg, W. G., C. R. Woese, M. E. Dobson, and E. A. Weiss. 1985. Common origin of rickettsiae and certain plant pathogens. Science 230:556-558.

49. White, F. F., and E. W. Nester. 1980. Hairy root: plasmid encodes virulence traits in Agrobacterium rhizogenes. J. Bacteriol. 141:1134-1141.

50. White, L. O. 1972. The taxonomy of the crown-gall organism Agrobacterium tumefaciens and its relationship to rhizobia and other agrobacteria. J. Gen. Microbiol. 72:565-574.

51. Yang, D., Y. Oyaizu, H. Oyaizu, G. J. Olsen, and C. R. Woese. 1985. Mitochondrial origins. Proc. Natl. Acad. Sci. USA 82: $4443-4447$

52. Zaenen, I., N. VanLarebeke, H. Teuchy, M. VanMontagu, and J. Schell. 1974. Supercoiled circular DNA in crown gall inducing Agrobacterium strains. J. Mol. Biol. 86:109-127. 